Check for updates

Cite this: RSC Adv., 2021, 11, 27589

\title{
Soft synthesis and characterization of goethite- based nanocomposites as promising cyclooctene oxidation catalysts $\uparrow$
}

\author{
Andrei Cristian Kuncser,,$^{\mathrm{t}} \mathrm{a}$ Ioana Dorina Vlaicu, (D) $\ddagger^{\mathrm{a}}$ Octavian Dumitru Pavel, (D) ${ }^{\mathrm{b}}$ \\ Rodica Zavoianu, (DD ${ }^{\mathrm{b}}$ Mihaela Badea, ${ }^{\mathrm{C}}$ Dana Radu, ${ }^{\mathrm{a}}$ Daniela Cristina Culita, \\ Arpad Mihai Rostas (D) *a and Rodica Olar (iD)*c
}

\begin{abstract}
Goethite based nanocomposites with a different composition such as $6 \mathrm{FeO}(\mathrm{OH}) \cdot \mathrm{MnO}(\mathrm{OH}) \cdot 0.5 \mathrm{H}_{2} \mathrm{O}(\mathrm{Mn}$ composite), $x \mathrm{FeO}(\mathrm{OH}) \cdot \mathrm{M}(\mathrm{OH})_{2} \cdot \mathrm{yH}_{2} \mathrm{O}(\mathrm{Co}$-composite (M: Co, $x=12, y=3)$, Ni-composite (M: Ni, $x=7$, $y=2))$ and $x \mathrm{FeO}(\mathrm{OH}) \cdot \mathrm{MO} \cdot \mathrm{yH}_{2} \mathrm{O}(\mathrm{Cu}$-composite $(\mathrm{M}: \mathrm{Cu}, x=5.5, y=3)$, Zn-composite $(\mathrm{M}: \mathrm{Zn}, x=6, y=$ 1.5)) have been prepared by a soft chemical synthesis consisting in acetate hydrolysis. The data provided by Fourier transform infrared (FTIR), ultraviolet-visible-near infrared (UV-Vis-NIR), electron paramagnetic resonance (EPR) and Mössbauer spectra account for a slight modification of all composites' physicochemical properties compared to the starting material. Powder X-ray diffraction and transmission electron microscopy (TEM) investigations revealed the secondary phase nature and presence along with that of goethite. The TEM data are also consistent with a nano rod-like morphology with a 5-10 nm width and an average length of $40 \mathrm{~nm}$. The catalytic oxidation of cyclooctene with $\mathrm{O}_{2}$ using isobutyraldehyde as reductant and acetonitrile as a solvent was performed in batch conditions for $5 \mathrm{~h}$ at room temperature. The selectivity for the epoxide was higher than $99 \%$ for all tested solids. The conversion of cyclooctene decreased from $55 \%$ to $4 \%$ following the same order of variance as the base/ acid sites ratio: $\mathrm{Mn}$-composite $>\mathrm{Fe}$-composite $>$ Co-composite $>\mathrm{Ni}$-composite $>$ Zn-composite $>\mathrm{Cu}$ composite. The $6 \mathrm{FeO}(\mathrm{OH}) \cdot \mathrm{MnO}(\mathrm{OH}) \cdot 0.5 \mathrm{H}_{2} \mathrm{O}(\mathrm{Mn}$-composite) exhibited the most promising catalytic activity in cyclooctene oxidation, which can be correlated with the redox ability of $\mathrm{Mn}(\mathrm{III})$ combined with the increased base character of this solid. The catalytic activity of this sample decreases by $10 \%$ after

several successive reaction cycles.
\end{abstract}

\author{
Received 31st May 2021
Accepted 1st August 2021 \\ Received 31st May 2021
Accepted 1st August 2021 \\ DOI: 10.1039/d1ra04211d \\ rsc.li/rsc-advances
}

\section{Introduction}

The low production costs and their chemical stability against UV radiation or corrosive agents make inorganic pigments one of the most important species of this type. Among these, both iron oxides and oxyhydroxides such $\gamma-\mathrm{Fe}_{2} \mathrm{O}_{3}$ (maghemite), $\mathrm{Fe}_{3} \mathrm{O}_{4}$ (magnetite), $\alpha-\mathrm{FeO}(\mathrm{OH})$ (goethite), and $\mathrm{FeO}(\mathrm{OH}) \cdot \mathrm{H}_{2} \mathrm{O}$ (limonite) are constituents of many paints, enamels, and

\footnotetext{
${ }^{a}$ National Institute of Materials Physics, Laboratory of Atomic Structures and Defects in Advanced Materials, 405A Atomiștilor Str., Măgurele, Ilfov, 077125, Romania. E-mail: arpad.rostas@infim.ro

${ }^{b}$ University of Bucharest, Faculty of Chemistry, Department of Organic Chemistry, Biochemistry and Catalysis, 4-12 Regina Elisabeta Av. S3, Bucharest, 030018, Romania

'University of Bucharest, Faculty of Chemistry, Department of Inorganic Chemistry, 9092 Panduri Str., 050663, Bucharest, Romania.E-mail: rodica.olar@chimie.unibuc.ro ${ }^{d}$ Ilie Murgulescu Institute of Physical Chemistry, 202 Splaiul Independentei, 060021, Bucharest, Romania

$\dagger$ Electronic supplementary information (ESI) available. See DOI: 10.1039/d1ra04211d

\$ These authors provided an equal contribution.
}

varnishes. $^{\mathbf{1 , 2}}$ On the other hand, all ores enriched in such compounds represent the raw material for the cast or steel iron industry. ${ }^{3,4}$

Some concrete based on limonite or ilmenite-limonite is used as nuclear reactor shielding. ${ }^{5-7}$ Both goethite and limonite are used as precursors for preparing many functional materials such as magnetic oxides, maghemite, magnetite, and ferrites. ${ }^{8-10}$ Moreover, the limonite addition to lithium-ion batteries increases the ionic resistance and conductivity. ${ }^{\mathbf{1 1}, \mathbf{1 2}} \mathrm{A}$ limonite-doped lithium borate glass was developed as gammaray shielding material. ${ }^{13}$

Natural limonite was also used as raw material to produce a nanosized zero-valent iron by hydrogen reduction with superior performance on $p$-nitrophenol decomposition compared with a commercial iron powder. ${ }^{14}$ Furthermore, a cotton fabric coated with a polymer containing a mixture of goethite, limonite, and hematite as additives exhibited bacteriostatic and antibacterial effects against Staphylococcus aureus and Escherichia coli. ${ }^{\mathbf{1 5}}$

Far from these various applications, other studies use hydrated iron oxyhydroxide as a catalyst for inorganic and 
organic processes. Examples of such methods are arsenite oxidation, ${ }^{\mathbf{1 6}}$ arsenic removal from wastewater, ${ }^{17}$ ammonia, ${ }^{18}$ pyridine $^{19}$ or hydrogen sulphide ${ }^{20}$ removal from coke oven gas, coal liquefaction for oil production, ${ }^{21}$ organic compounds removing from wastewater ${ }^{22-25}$ and microcystin-LR hydrolysis in cancer prevention. ${ }^{26}$

On the other hand, iron-containing systems containing bimetallic $^{27-33}$ or trimetallic layered oxyhydroxides ${ }^{27,34-36}$ were developed, based on their tunable electronic structures and rich active sites, ${ }^{37}$ as valuable nonprecious metal-based materials for oxygen evolution reaction (OER).

Synthesis of this kind of compounds with controlled size, shape, morphology, iron substitution, and the active surface is important. Moreover, since their properties are affected by all these factors, they also need to be precisely tuned depending on the requirements of particular applications. ${ }^{38,39}$

Usually, goethite is mainly obtained by the wet-chemical precipitation process starting from water-soluble iron salts (chloride, nitrate, or sulfate) by adding either caustic soda or ammonia in the presence of air as oxidizing agent. ${ }^{40}$ Parameters like $\mathrm{pH}$, salt concentration, temperature, and stirring velocity are involved in the particle size and geometry, which control the properties. ${ }^{38,39}$

However, the attention in this field is now focused on the development of some non-conventional methods such as plasma treatment, ${ }^{24,25}$ electrodeposition, ${ }^{27,30,31,34}$ chemical deposition, ${ }^{29,32}$ or chemical deposition assisted by a magnetic field. ${ }^{33}$ Moreover, all these methods are eco-friendly and control both the nano-dimension of the particles and the substitution degree.

In the present work, we extended the study to obtain manganese, nickel, cobalt, copper, and zinc goethite-based nanocomposites by a soft chemical method successfully used for some ferrites synthesis. ${ }^{41}$ Furthermore, the influence of the second metallic ion from these nanocomposites on their catalytic behavior in cyclooctene epoxidation with molecular oxygen, in the presence of isobutyraldehyde, under ambient conditions was studied as well.

\section{Experimental part}

\section{Reagents}

We used high purity reagents purchased from Sigma-Aldrich (Saint-Louis, MO, USA) $\left(\mathrm{FeCl}_{3} \cdot 6 \mathrm{H}_{2} \mathrm{O}, \mathrm{Mn}\left(\mathrm{CH}_{3} \mathrm{COO}\right)_{2} \cdot 4 \mathrm{H}_{2} \mathrm{O}\right.$, $\mathrm{Co}\left(\mathrm{CH}_{3} \mathrm{COO}\right)_{2} \cdot 4 \mathrm{H}_{2} \mathrm{O}, \mathrm{Ni}\left(\mathrm{CH}_{3} \mathrm{COO}\right)_{2} \cdot 4 \mathrm{H}_{2} \mathrm{O}, \mathrm{Cu}\left(\mathrm{CH}_{3} \mathrm{COO}\right)_{2} \cdot \mathrm{H}_{2} \mathrm{O}$, $\mathrm{Zn}\left(\mathrm{CH}_{3} \mathrm{COO}\right)_{2} \cdot 2 \mathrm{H}_{2} \mathrm{O}$, ammonia $\left.25 \%, \mathrm{H}_{2} \mathrm{O}_{2}\right)$ as received without further purification. Cyclooctene, isobutyraldehyde, and acetonitrile were also purchased from Sigma-Aldrich and have been previously distilled before reactions. Gaseous $\mathrm{O}_{2}$ with 99.99\% purity purchased from Linde gas was used as an oxidant agent.

\section{Instruments and methods}

Chemical analysis of iron, manganese, cobalt, nickel, copper, and zinc was performed using the usual micro methods $\mathrm{s}^{\mathbf{4 2}}$ after sample dissolution with hydrochloric acid. The iron was precipitated with ammonia and gravimetrically determined after calcination, while the other metallic ions were determined from the resulted solution. The heating curves (TG, DTG, and DTA) were recorded using a Labsys 1200 instrument (Setaram, Caluire, France), with a sample mass of about $20 \mathrm{mg}$ over the temperature range of $293-1173 \mathrm{~K}$, using a heating rate of 10 $\mathrm{K} \mathrm{min}^{-1}$. The measurements were carried out in a synthetic air atmosphere (flow rate of $16.70 \mathrm{~cm}^{3} \mathrm{~min}^{-1}$ ) using alumina crucibles. The Fourier transform infrared (FTIR) spectra were recorded with a Spectrum BX II (Perkin Elmer, USA) spectrometer in the $350-4000 \mathrm{~cm}^{-1}$ range by accumulating 32 scans at a resolution of $4 \mathrm{~cm}^{-1}$. The powdered samples were diluted into $\mathrm{KBr}$ powder in a 1:100 mass ratio, ground thoroughly, and pressed into pellets. UV-Vis spectroscopy was performed in solid-state on a V 670 spectrophotometer (Jasco, Easton, MD, USA) with Spectralon as standard in the 200-1500 $\mathrm{nm}$ range. The electron paramagnetic resonance (EPR) spectroscopy measurements were carried out with a Bruker EMX premium X (Bruker, Karlsruhe, Germany) equipped with an X-SHQ 4119HSW1 X-Band resonator at a microwave frequency of $9.4457 \mathrm{GHz}$ and power of $0.06325 \mathrm{~mW}$. Further measurements parameters were: conversion time $10 \mathrm{~ms}$, time constant $5.12 \mathrm{~ms}$, modulation amplitude $0.3 \mathrm{mT}$ with one scan. We used a digital temperature control system ER 4131VT with a liquid nitrogen cryostat from Bruker (Bruker, Karlsruhe, Germany) for cooling. The ${ }^{57} \mathrm{Fe}$ Mössbauer spectra have been obtained in transmission geometry, at $6 \mathrm{~K}$ and room temperature, by inserting the samples in a close cycle Janis cryostat (Edina, Minnesota, USA). A SEECO-type spectrometer (Edina, Minnesota, USA) operating under the constant acceleration mode and a ${ }^{57} \mathrm{Co}(\mathrm{Rh})$ radioactive source of about $30 \mathrm{mCi}$ activity were used. The acquired ${ }^{57} \mathrm{Fe}$ Mössbauer spectra were analyzed using the NORMOS software, which allows the decomposition of the measured absorption pattern in spectral components corresponding to different iron non-equivalent positions. In the case of a continuous distribution of the hyperfine parameters, the fitting procedure can be performed accordingly using specific routines that provide the envisaged probability distribution function and complementary average hyperfine parameters. The isomer shift is reported relative to the isomer shift of metallic Fe at room temperature. Powder X-ray diffraction (XRD) patterns were recorded with a Bruker D8 Advance X-ray diffractometer (Bruker, Karlsruhe, Germany) (Cu anode and Ni filter, $\lambda=1.54184 \AA$ ) in Bragg-Brentano configuration. We determined the lattice parameters and the average crystallites size by the Rietveld refinement $\operatorname{method}^{43}$ using the MAUD software. The JEOL 2100 Transmission Electron Microscope (TEM) (Tokyo, Japan), equipped with energy dispersive X-ray (EDS), has been used for transmission electron microscopy investigations. Specimens have been prepared using the standard powder method.

\section{General procedure for goethite and goethite-based nanocomposites synthesis}

The goethite was synthesized by adding $10 \mathrm{~mL}$ solution $25 \%$ $\mathrm{NH}_{3}$ to a solution of $10 \mathrm{~g} \mathrm{FeCl}_{3} \cdot 6 \mathrm{H}_{2} \mathrm{O}$ in $100 \mathrm{~mL}$ distilled water. The reaction mixture was stirred at room temperature for $1 \mathrm{~h}$ 
until a brown precipitate formed. The solid product was filtered off, washed several times with water, and air-dried.

The syntheses of goethite-nanocomposites were performed by adding $20 \mathrm{mmol}$ freshly prepared goethite to solutions containing $10 \mathrm{mmol} \mathrm{M}\left(\mathrm{CH}_{3} \mathrm{COO}\right)_{2} \cdot n \mathrm{H}_{2} \mathrm{O}$ (M: $\mathrm{Mn}, \mathrm{Co}, \mathrm{Ni}, \mathrm{Cu}$, and $\mathrm{Zn})$ in $100 \mathrm{~mL}$ water. Reaction mixtures were heated at $373 \mathrm{~K}$ under continuous stirring for $24 \mathrm{~h}$. The obtained brown products were filtered off, washed several times with water, and airdried.

\section{Textural characterization}

Nitrogen adsorption-desorption isotherms at $77 \mathrm{~K}$ were recorded on a Micromeritics ASAP 2020 automated gas adsorption system (Norcross, GA, USA). The samples were degassed at $90{ }^{\circ} \mathrm{C}$ for 12 hours under vacuum before analysis. Specific surface areas $\left(S_{\mathrm{BET}}\right)$ were calculated according to the BrunauerEmmett-Teller (BET) equation, using adsorption data in the relative pressure range between 0.05 and 0.30 . The total pore volume $\left(V_{\text {total }}\right)$ was estimated from the amount adsorbed at the relative pressure of 0.99 . The pore size distribution curves were obtained from the adsorption data using a DFT (density functional theory) model.

\section{Catalytic tests}

This study evaluates the catalytic activities of the synthesized materials in the oxidation of cyclooctene with molecular oxygen. We used isobutyraldehyde as a reductant and acetonitrile as a solvent in batch conditions. Thus, $20 \mathrm{mg}$ of material were contacted with $0.04 \mathrm{~mol}$ cyclooctene and $0.08 \mathrm{~mol}$ isobutyraldehyde in $10 \mathrm{~mL}$ acetonitrile as a solvent. We performed the catalytic tests for $5 \mathrm{~h}$ at room temperature. Molecular oxygen was admitted in a sealed stirred flask of $250 \mathrm{~mL}$ by a tube linked to an oxygen pressurized cylinder employing a manometer. During the tests, the oxygen pressure was maintained at $1 \mathrm{~atm}$. Before reactants and the catalyst admission in the reactor, the air was removed by purging molecular oxygen for 5 minutes. During the reaction, at each hour, quantities of $50 \mu \mathrm{L}$ were extracted from the reactor and analyzed with a Gas Thermo Quest Chromatograph (ThermoFisher Scientific Inc., Waltham, MA, USA) equipped with an FID detector and a capillary column with DB5 stationary phase. All products, as well as reactants, were identified by comparison with standard samples (retention time in GC) and by mass spectrometer-coupled chromatography VARIAN SATURN 2100 T (LabX, Midland, ON, Canada) to evaluate the cyclooctene conversion and the selectivity to epoxide.

\section{Base sites determination}

The total number of base sites was determined using the irreversible adsorption of acrylic acid $\left(\mathrm{p} K_{\mathrm{a}}=4.2\right)$. Samples of dried solids $(0.05 \mathrm{~g}$ ) were contacted for 2 hours (duration required for reaching the equilibrium in the liquid-solid system) with $10 \mathrm{~mL}$ of $0.01 \mathrm{M}$ solution of acrylic acid in cyclohexane in brown sealed bottles under mild stirring $(150 \mathrm{rpm})$ at room temperature. It was assumed that the interaction of the solids with atmospheric $\mathrm{CO}_{2}$ and water was negligible since the samples were exposed to the atmosphere only during weighing. The concentration of the acrylic acid remaining in the solution after reaching equilibrium was determined by UV-Vis spectrometry at $\lambda_{\max }=225 \mathrm{~nm}$ using the Jasco V-650 spectrometer (Tokyo, Japan). For each solid sample, 3 parallel determinations were performed, and the obtained results were averaged. The amount of acrylic acid (AA) adsorbed was calculated with the formula:

$$
\mathrm{AA}_{\mathrm{i}}-\mathrm{AA}_{\mathrm{f}}=\mathrm{AA}_{\mathrm{ads}}
$$

where indexes $i$ and $f$ refer to the initial amount and the final amount of acrylic acid in the solution, respectively.

The method is inspired by the one used to determine base sites in hydrotalcite-type materials. ${ }^{44}$ However, in the case of these solids, we could not use phenol for the separate determination of strong base sites since phenol is known to give colored combinations with iron.

The total concentration of base sites was calculated with the formula:

$$
C_{\mathrm{B}}=\mathrm{AA}_{\mathrm{ads}} / \mathrm{wt}[\mathrm{mmoles} \mathrm{AA} / \mathrm{gram} \text { of sample }]
$$

where wt is the weight of the solid sample.

\section{Acid sites determination}

The total number of acid sites was determined by pyridine adsorption. The distribution of acid sites, Lewis and Brönsted, respectively, were calculated from the areas of the corresponding peaks in the DRIFT spectra recorded on FT/IR-4700 Jasco spectrometer (Tokyo, Japan). Samples of dried solids (0.05 grams) were contacted with pyridine aliquots $(0.2 \mu \mathrm{L}$ each $)$ and maintained under inert flow at $90{ }^{\circ} \mathrm{C}$ for the removal of physisorbed pyridine. The procedure was repeated until the weight of the sample after two consecutive additions of pyridine was constant (did not vary with more than $0.0001 \mathrm{~g}$ ). Then, the DRIFT spectrum of the sample with adsorbed pyridine was recorded, considering the DRIFT spectrum of the freshly dried solid as background. According to literature data, ${ }^{45-47}$ the bands corresponding to pyridine adsorbed on Lewis acid sites appear in the ranges of $1435-1455$ and $1570-1615 \mathrm{~cm}^{-1}$ while those corresponding to pyridine adsorbed on Brönsted acid sites appear in the range of $1520-1555$ and at $1630 \mathrm{~cm}^{-1}$. In the ESI, $\dagger$ we have included Fig. S1 $\uparrow$ with the DRIFT spectra of the pyridine adsorbed on the samples.

\section{Results and discussions}

In this paper, we report the synthesis and characterization of some goethite based nanocomposites of type: $6 \mathrm{FeO}(\mathrm{OH})$. $\mathrm{MnO}(\mathrm{OH}) \cdot 0.5 \mathrm{H}_{2} \mathrm{O}$ (Mn-composite), $x \mathrm{FeO}(\mathrm{OH}) \cdot \mathrm{M}(\mathrm{OH})_{2} \cdot y \mathrm{H}_{2} \mathrm{O}$ (Co-composite (M: Co, $x=12, y=3$ ) and Ni-composite ( $\mathrm{M}: \mathrm{Ni}, x$ $=7, y=2))$ and $x \mathrm{FeO}(\mathrm{OH}) \cdot \mathrm{MO} \cdot y \mathrm{H}_{2} \mathrm{O}(\mathrm{Cu}$-composite $(\mathrm{M}: \mathrm{Cu}, x=$ $5.5, y=3$ ) and $\mathrm{Zn}$-composite (M: $\mathrm{Zn}, x=6, y=1.5)$ ), respectively. These nanocomposite materials were synthesized by the transition ion acetates hydrolyze in an aqueous suspension of freshly prepared $\mathrm{FeO}(\mathrm{OH}) \cdot \mathrm{H}_{2} \mathrm{O}$ as presented in reactions (1)-(3). This process is accompanied by $\mathrm{Mn}$ (II) to $\mathrm{Mn}$ (III) oxidation and $\mathrm{M}(\mathrm{OH})_{2}$ into $\mathrm{MO}$ transformation in the case of $\mathrm{Cu}$ (II) and $\mathrm{Zn}$ (II). 
Table 1 Analytical and thermal data for goethite-based nanocomposites

\begin{tabular}{|c|c|c|c|c|c|c|c|c|c|c|}
\hline \multirow[b]{2}{*}{ Compound (notation) } & \multicolumn{2}{|l|}{$\% \mathrm{Fe}$} & \multicolumn{2}{|l|}{$\% \mathrm{M}$} & \multicolumn{2}{|c|}{$\%$ residue } & \multicolumn{2}{|l|}{$\% W_{1}$} & \multicolumn{2}{|l|}{$\% W_{2}$} \\
\hline & Calc. & Exp. & Calc. & Exp. & Calc. & Exp. & Calc. & Exp. & Calc. & Exp. \\
\hline $\begin{array}{l}6 \mathrm{FeO}(\mathrm{OH}) \cdot \mathrm{MnO}(\mathrm{OH}) \cdot 0.5 \mathrm{H}_{2} \mathrm{O}\left(\mathrm{Mn}^{-}\right. \\
\text {composite })\end{array}$ & 53.18 & 53.07 & 8.96 & 8.53 & 88.56 & 89.03 & 1.43 & 1.10 & 10.01 & 9,87 \\
\hline $\begin{array}{l}12 \mathrm{FeO}(\mathrm{OH}) \cdot \mathrm{Co}(\mathrm{OH})_{2} \cdot 3 \mathrm{H}_{2} \mathrm{O}\left(\mathrm{Co}^{-}\right. \\
\text {composite })\end{array}$ & 55.24 & 55.19 & 4.86 & 4.75 & 85.16 & 85.31 & 4.45 & 4.42 & 10.39 & 10.27 \\
\hline $7 \mathrm{FeO}(\mathrm{OH}) \cdot \mathrm{Ni}(\mathrm{OH})_{2} \cdot 2 \mathrm{H}_{2} \mathrm{O}($ Ni-composite $)$ & 52.07 & 52.00 & 7.82 & 7.68 & 84,39 & 84.58 & 4.80 & 4.71 & 10.80 & 10.71 \\
\hline $5.5 \mathrm{FeO}(\mathrm{OH}) \cdot \mathrm{CuO} \cdot 3 \mathrm{H}_{2} \mathrm{O}(\mathrm{Cu}$ composite $)$ & 49.36 & 49.22 & 10.21 & 10.15 & 83.36 & 83.51 & 8.68 & 8.60 & 7.96 & 7.89 \\
\hline $6 \mathrm{FeO}(\mathrm{OH}) \cdot \mathrm{ZnO} \cdot 1.5 \mathrm{H}_{2} \mathrm{O}(\mathrm{Zn}$ composite $)$ & 52.29 & 52.14 & 10.20 & 10.02 & 87.37 & 87.54 & 4.21 & 4.15 & 8.42 & 8.31 \\
\hline
\end{tabular}

These samples were characterized as nanocomposites by chemical and thermal analysis, IR, UV-Vis-NIR, EPR, and Mössbauer spectroscopy. Simultaneously, their morphology and particle dimension was provided by powder X-ray diffraction and TEM studies. Textural parameters were calculated from $\mathrm{N}_{2}$ sorption isotherms.

\section{Chemical analysis and thermal decomposition}

We deduced the composition of these species from the metal contents, the mass of water lost up to $423 \mathrm{~K}\left(W_{1}\right)$, the mass of water lost up to $633 \mathrm{~K}\left(W_{2}\right)$, and residue formed at $873 \mathrm{~K}$ during the thermal decomposition, as reported in Table 1.

The thermal decomposition of all samples occurs in two endothermic steps. The first step corresponds to crystallization water elimination, which occurs up to 413-523 K, followed immediately by the same compound elimination due to oxyhydroxide/hydroxide decomposition.

\section{IR spectroscopy investigations}

Iron oxyhydroxides, $\mathrm{FeO}(\mathrm{OH}) \cdot n \mathrm{H}_{2} \mathrm{O}$ consists of a vast array of oxo and hydroxo groups with a three-dimensional structure in which the layers are connected through hydrogen bonds. The basic units in these polynuclear species that generate specific bands in the IR spectra of goethite consist of groups of two or three Fe(III) ions links by oxo or hydroxo bridged units. Essential bands noticed in the spectra of synthesized goethite-based nanocomposites are summarized in Table 2. The infrared spectra are presented in Fig. $\mathrm{S} 2$ in the ESI. $\dagger$
In the $3130-3410 \mathrm{~cm}^{-1}$ region, one can notice two broad bands assigned to $\nu(\mathrm{OH})$ asymmetric and symmetric stretching vibration modes for lattice water. The bands around 1600 $(\nu(\mathrm{OH})), 890,800\left(\rho_{\mathrm{r}}\left(\mathrm{OH}_{2}\right)\right)$, and $600 \mathrm{~cm}^{-1}\left(\rho_{\mathrm{w}}\left(\mathrm{OH}_{2}\right)\right)$ are also due to the water molecule vibration modes. Moreover, the last ones indicate that some of these molecules are coordinated to the metallic centers. The hydroxo groups are distinguished from the aqua ones by the appearance of bands in the range 1115$1140 \mathrm{~cm}^{-1}$ assigned to $\delta(\mathrm{M}-\mathrm{OH})$. Two bands assigned to metaloxygen stretching vibrations appear in all spectra in the 400$460 \mathrm{~cm}^{-1}$ range. ${ }^{48}$

$6 \mathrm{FeO}(\mathrm{OH}) \cdot \mathrm{H}_{2} \mathrm{O}+\mathrm{Mn}\left(\mathrm{CH}_{3} \mathrm{COO}\right)_{2}+0.5 \mathrm{O}_{2} \rightarrow 6 \mathrm{FeO}(\mathrm{OH}) \cdot$ $\mathrm{MnO}(\mathrm{OH}) \cdot 0.5 \mathrm{H}_{2} \mathrm{O}+2 \mathrm{CH}_{3} \mathrm{COOH}+3.5 \mathrm{H}_{2} \mathrm{O}$

$x \mathrm{FeO}(\mathrm{OH}) \cdot \mathrm{H}_{2} \mathrm{O}+\mathrm{M}\left(\mathrm{CH}_{3} \mathrm{COO}\right)_{2} \rightarrow x \mathrm{FeO}(\mathrm{OH}) \cdot \mathrm{M}(\mathrm{OH})_{2} \cdot y \mathrm{H}_{2} \mathrm{O}$ $+2 \mathrm{CH}_{3} \mathrm{COOH}+(x-y-2) \mathrm{H}_{2} \mathrm{O}(\mathrm{M}: \mathrm{Co}, \mathrm{Ni})$

$x \mathrm{FeO}(\mathrm{OH}) \cdot \mathrm{H}_{2} \mathrm{O}+\mathrm{M}\left(\mathrm{CH}_{3} \mathrm{COO}\right)_{2} \rightarrow x \mathrm{FeO}(\mathrm{OH}) \cdot \mathrm{MO} \cdot y \mathrm{H}_{2} \mathrm{O}+$ $2 \mathrm{CH}_{3} \mathrm{COOH}+(x-y-1) \mathrm{H}_{2} \mathrm{O}(\mathrm{M}: \mathrm{Cu}, \mathrm{Zn})$

\section{UV-Vis-NIR spectroscopy characterization}

The UV-Vis-NIR spectroscopy proved to be a valuable tool to establish the oxidation state of transition ions. We used the goethite itself for baseline calibration and as a reference to eliminate the iron interference. In this condition, this method revealed only the $\mathrm{d}-\mathrm{d}$ bands characteristic for the second

Table 2 Absorption maxima in IR spectra of the samples (the notations: vs - very strong, s - strong, $\mathrm{m}$ - medium, and $\mathrm{w}$ - weak describes the signal intensities)

\begin{tabular}{|c|c|c|c|c|c|c|}
\hline $\mathrm{FeO}(\mathrm{OH})$ & Mn-composite & Co-composite & Ni-composite & Cu-composite & Zn-composite & Assignment \\
\hline $3410 \mathrm{~m}$ & $3410 \mathrm{~m}$ & $3410 \mathrm{~m}$ & $3420 \mathrm{~m}$ & $3380 \mathrm{~m}$ & $3410 \mathrm{~m}$ & $\nu_{\text {asym }}\left(\mathrm{H}_{2} \mathrm{O}\right)$ \\
\hline $3140 \mathrm{~s}$ & $3130 \mathrm{~s}$ & $3130 \mathrm{~s}$ & $3130 \mathrm{~s}$ & $3140 \mathrm{~m}$ & $3140 \mathrm{~m}$ & $\nu_{\mathrm{sym}}\left(\mathrm{H}_{2} \mathrm{O}\right)$ \\
\hline $1640 \mathrm{w}$ & $1640 \mathrm{w}$ & $1640 \mathrm{w}$ & $1600 \mathrm{w}$ & $1645 \mathrm{w}$ & $1620 \mathrm{w}$ & $\delta\left(\mathrm{H}_{2} \mathrm{O}\right)$ \\
\hline $1140 \mathrm{w}$ & $1115 \mathrm{w}$ & $1125 \mathrm{w}$ & $1130 \mathrm{vw}$ & $1120 \mathrm{w}$ & $1115 \mathrm{w}$ & $\delta(\mathrm{M}-\mathrm{OH})$ \\
\hline $890 \mathrm{~s}$ & $895 \mathrm{~m}$ & $895 \mathrm{~s}$ & $895 \mathrm{~s}$ & $890 \mathrm{~m}$ & $900 \mathrm{~m}$ & $\rho_{\mathrm{r}}\left(\mathrm{OH}_{2}\right)$ \\
\hline $800 \mathrm{~s}$ & $800 \mathrm{~m}$ & $800 \mathrm{~s}$ & $795 \mathrm{~s}$ & $800 \mathrm{~m}$ & $795 \mathrm{~m}$ & \\
\hline $610 \mathrm{~s}$ & $605 \mathrm{~m}$ & $600 \mathrm{~s}$ & $605 \mathrm{~s}$ & $600 \mathrm{~m}$ & $605 \mathrm{~m}$ & $\rho_{\mathrm{w}}\left(\mathrm{OH}_{2}\right)$ \\
\hline 455 vs & 460 vs & $460 \mathrm{vs}$ & $450 \mathrm{~s}$ & 460 vs & 460 vs & $\nu(\mathrm{M}-\mathrm{O})$ \\
\hline $410 \mathrm{vs}$ & 410 vs & $410 \mathrm{vs}$ & 410 vs & 410 vs & 410 vs & \\
\hline
\end{tabular}


transition metallic ion present in the composite network. Thus, the Mn-composite exhibits two bands at 9130 and $14925 \mathrm{~cm}^{-1}$. These are assigned to spin allowed transitions ${ }^{5} \mathrm{~B}_{1 \mathrm{~g}} \rightarrow{ }^{5} \mathrm{~B}_{2 \mathrm{~g}}$ and ${ }^{5} \mathrm{~B}_{1 \mathrm{~g}} \rightarrow{ }^{5} \mathrm{~A}_{1 \mathrm{~g}}$ in an octahedral stereochemistry associated with
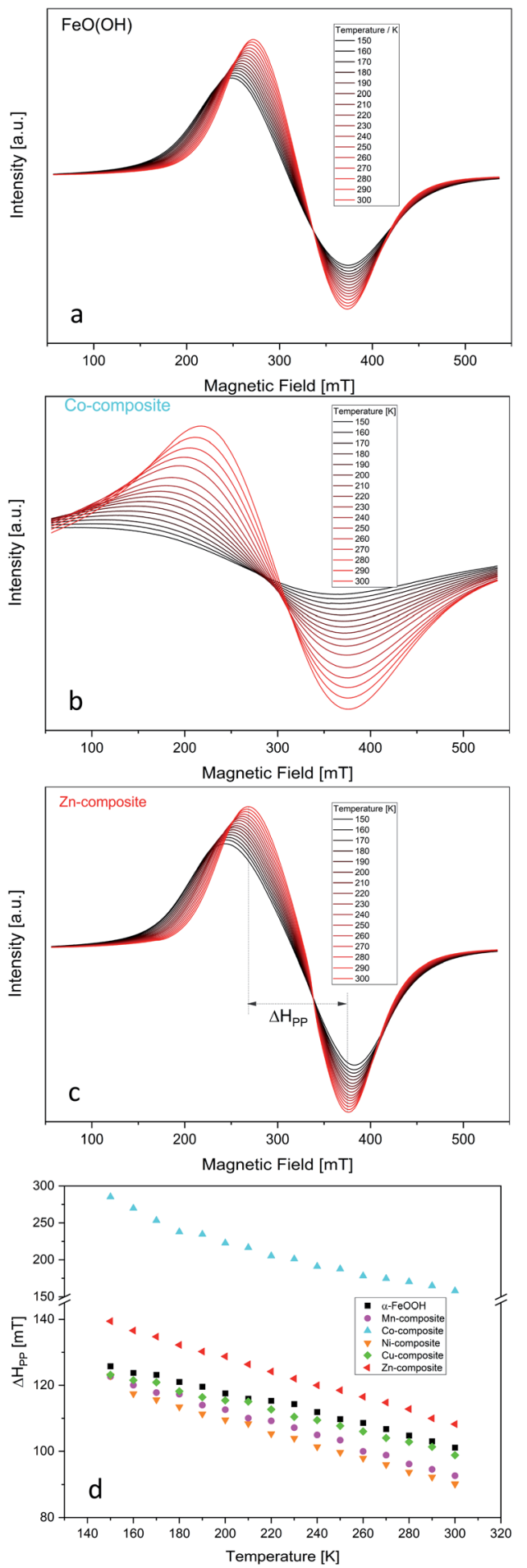

Fig. 1 Temperature dependency of the EPR spectra for FeO(OH) (a), Co-composite (b) and Zn-composite (c). Temperature dependency of the peak-to-peak line width of the EPR spectra of the goethite and goethite-based nanocomposites (d). The temperature was varied in 10 $\mathrm{K}$ per step in the range $150-300 \mathrm{~K}$. (a)

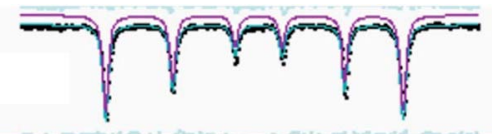

(b)

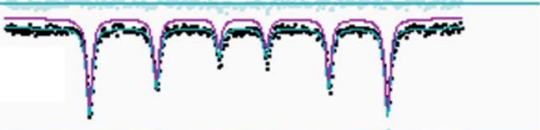

(c)

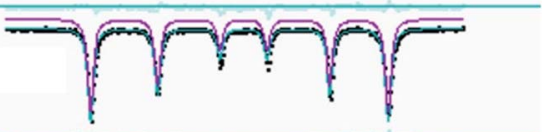

(d)

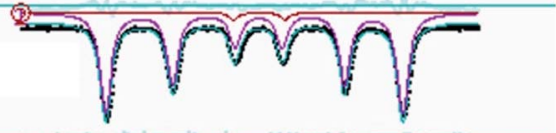

(e)

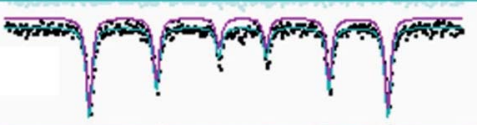

(f)

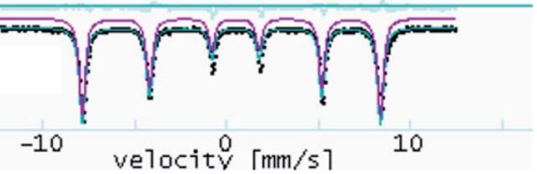

Fig. $2{ }^{57} \mathrm{Fe}$ Mössbauer absorption spectra at $6 \mathrm{~K}$ (black dots) and fit results (purple line) obtained on goethite and goethite nanocomposite samples: $\mathrm{FeO}(\mathrm{OH})$ (a), Cu-composite (b), Zn-composite (c), Mncomposite (d), Ni-composite (e) and Co-composite (f).

[Mn(III) $\mathrm{O}_{6}$ ] chromophore. The bands at 9660 and $17860 \mathrm{~cm}^{-1}$ for Co-composite arise from ${ }^{4} \mathrm{~T}_{1 \mathrm{~g}} \rightarrow{ }^{4} \mathrm{~T}_{2 \mathrm{~g}}$ and ${ }^{4} \mathrm{~T}_{1 \mathrm{~g}} \rightarrow{ }^{4} \mathrm{~T}_{1 \mathrm{~g}}$ spin allowed transitions in an octahedral stereochemistry of [Co(II) $\left.\mathrm{O}_{6}\right]$ chromophore. The similar chromophore $\left[\mathrm{Ni}(\mathrm{II}) \mathrm{O}_{6}\right]$ is responsible for the bands at 10310 and $23256 \mathrm{~cm}^{-1}$ assigned to ${ }^{3} \mathrm{~A}_{2 g} \rightarrow{ }^{3} \mathrm{~T}_{2 g}$ and ${ }^{3} \mathrm{~A}_{2 g} \rightarrow{ }^{3} \mathrm{~T}_{1 \mathrm{~g}}$ transitions, respectively. The large and unsymmetrical band located at $10200 \mathrm{~cm}^{-1}$ for $\mathrm{Cu}-$ composite accounts for a square-planar $\left[\mathrm{Cu}(\mathrm{II}) \mathrm{O}_{4}\right]$ chromophore and, as a result, can be assigned to $\mathrm{d}_{x y} \rightarrow \mathrm{d}_{x^{2}-y^{2}}$ transition. ${ }^{99}$

\section{EPR spectroscopy characterization}

We recorded each compound's EPR spectra at different temperatures beginning with $150 \mathrm{~K}$ being increased in $10 \mathrm{~K}$

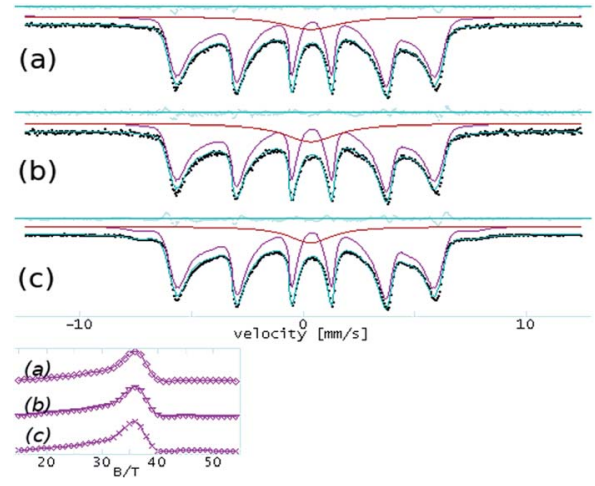

Fig. $3{ }^{57} \mathrm{Fe}$ Mössbauer spectra at room temperature on $\mathrm{FeO}(\mathrm{OH})(\mathrm{a})$, Mn-composite (b) and Co-composite (c). The inset shows corresponding hyperfine field distributions, with a maximum at $\sim 36 \mathrm{~T}$, consistent with the $\alpha-\mathrm{FeO}(\mathrm{OH})$ hyperfine field at room temperature. 
Table 3 Fit parameters on the investigated samples

\begin{tabular}{|c|c|c|c|c|c|c|}
\hline Sample/parameters & $\mathrm{FeO}(\mathrm{OH})$ & Cu-composite & Zn-composite & Mn-composite & Ni-composite & Co-composite \\
\hline ISO & 0.37 & 0.37 & 0.37 & 0.37 & 0.37 & 0.37 \\
\hline QUA & -0.24 & -0.24 & -0.23 & -0.24 & -0.24 & -0.24 \\
\hline $\mathrm{BHF}$ & 50.3 & 50.3 & 50.3 & 50.2 & 50.4 & 50.4 \\
\hline WID & 0.35 & 0.35 & 0.36 & 0.35 & 0.38 & 0.38 \\
\hline ISO & & 0.52 & & & & \\
\hline QUA & & 2.79 & & & & \\
\hline WID & & 0.53 & & & & \\
\hline
\end{tabular}

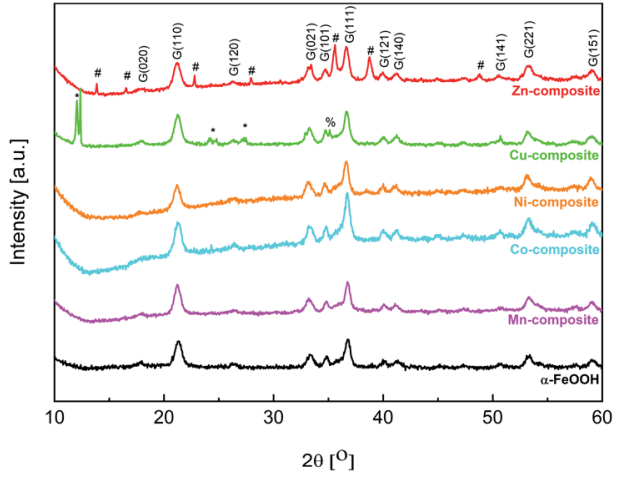

Fig. 4 Powder $X$-ray diffractograms for goethite and goethite-based nanocomposites (G - goethite, * - copper(॥) acetate, \# - ZnO (wurtzite), \% - $\mathrm{CuO}$ (tenorite)).

steps until $300 \mathrm{~K}$. The obtained characteristic spectra are presented in Fig. 1(a-c) for goethite, Co-composite, and $\mathrm{Zn}$ composite samples. The EPR spectra for the other goethitebased nanocomposites are shown in the ESI (Fig. S3†).

Table 4 Rietveld refinement data for goethite and goethitenanocomposites

\begin{tabular}{llc}
\hline Sample & $\begin{array}{l}\text { Lattice parameters } \\
a, b, c(\AA)\end{array}$ & $\begin{array}{l}\text { Mean crystallite size } \\
(\mathrm{nm})\end{array}$ \\
\hline FeO $(\mathrm{OH})$ & $\begin{array}{l}\text { } \\
9.598 \pm 0.001\end{array}$ & $17.9 \pm 0.31$ \\
& $3.017 \pm 0.002$ & \\
& $4.609 \pm 0.0006$ & $19.40 \pm 0.43$ \\
Mn-composite & $9.976 \pm 0.002$ & \\
& $3.011 \pm 0.0005$ & \\
Co-composite & $4.604 \pm 0.001$ & $19.40 \pm 0.43$ \\
& $9.950 \pm 0.002$ & \\
Ni-composite & $3.019 \pm 0.0006$ & \\
& $4.620 \pm 0.001$ & $20.97 \pm 0.43$ \\
& $9.977 \pm 0.002$ & \\
Cu-composite FeO $(\mathrm{OH})$ & $3.024 \pm 0.0007$ & \\
$88 \%$ & $9.617 \pm 0.0009$ & $20 \pm 0.34$ \\
& $9.955 \pm 0.002$ & \\
CuO 12\% & $3.024 \pm 0.0005$ & \\
& $4.684 \pm 0.001$ & $89.36 \pm 1.878$ \\
Zn-composite & $3.421 \pm 0.0006$ & \\
& $5.139 \pm 0.001$ & \\
& $4.588 \pm 0.001$ & $19.58 \pm 0.18$ \\
& $9.941 \pm 0.003$ & \\
& $3.016 \pm 0.0007$ &
\end{tabular}

The very broad EPR signal observed for all samples highlights the $\mathrm{FeO}(\mathrm{OH})$ strong ferromagnetic properties at low temperature. By increasing the temperature, the ferromagnetic properties vanish slowly, which is pointed out in Fig. 1d. The peak-to-peak line width of the EPR signal is plotted against the temperature. After reaching the Curie temperature, the material would become paramagnetic, and the peak-to-peak line width would present no changes. Since the Curie temperature of $\alpha$ $\mathrm{FeO}(\mathrm{OH})$ is located at about $900 \mathrm{~K},{ }^{50}$ this point was not reached in this study.

Regarding the changes in the peak-to-peak linewidths of the EPR spectra as a function of the temperature, it is clear that the used elements influenced the ferromagnetic behavior of the $\mathrm{FeO}(\mathrm{OH})$. Fig. 1d summarizes these changes, where cobalt induces the most significant changes in ferromagnetic behavior. The other elements presented in the composite network cause small but visible changes. Thus, the peak-to-peak line width temperature dependency is similar to the $\mathrm{FeO}(\mathrm{OH})$. $\mathrm{H}_{2} \mathrm{O}$ but different. This indicates a shift in the Currie temperature of the composites.

\section{Mössbauer spectroscopy characterization}

Due to the preparation conditions, a substitution effect of goethite can be considered. Therefore, we recorded the Mössbauer spectra of both goethite and goethite-based nanocomposites have to confirm or exclude this effect. Mössbauer absorption spectra obtained at $6 \mathrm{~K}$ on $\mathrm{FeO}(\mathrm{OH})$ and nanocomposite samples are shown in Fig. 2.

All the spectra show a sextet pattern characteristic to $\alpha$ $\mathrm{FeO}(\mathrm{OH})$ at low temperatures as the main component. The

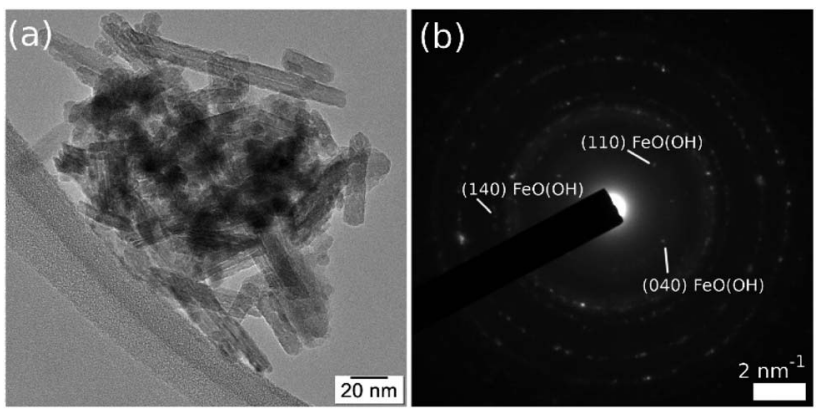

Fig. 5 TEM image (a) and corresponding SAED (b) on FeO $(\mathrm{OH})$ sample. 

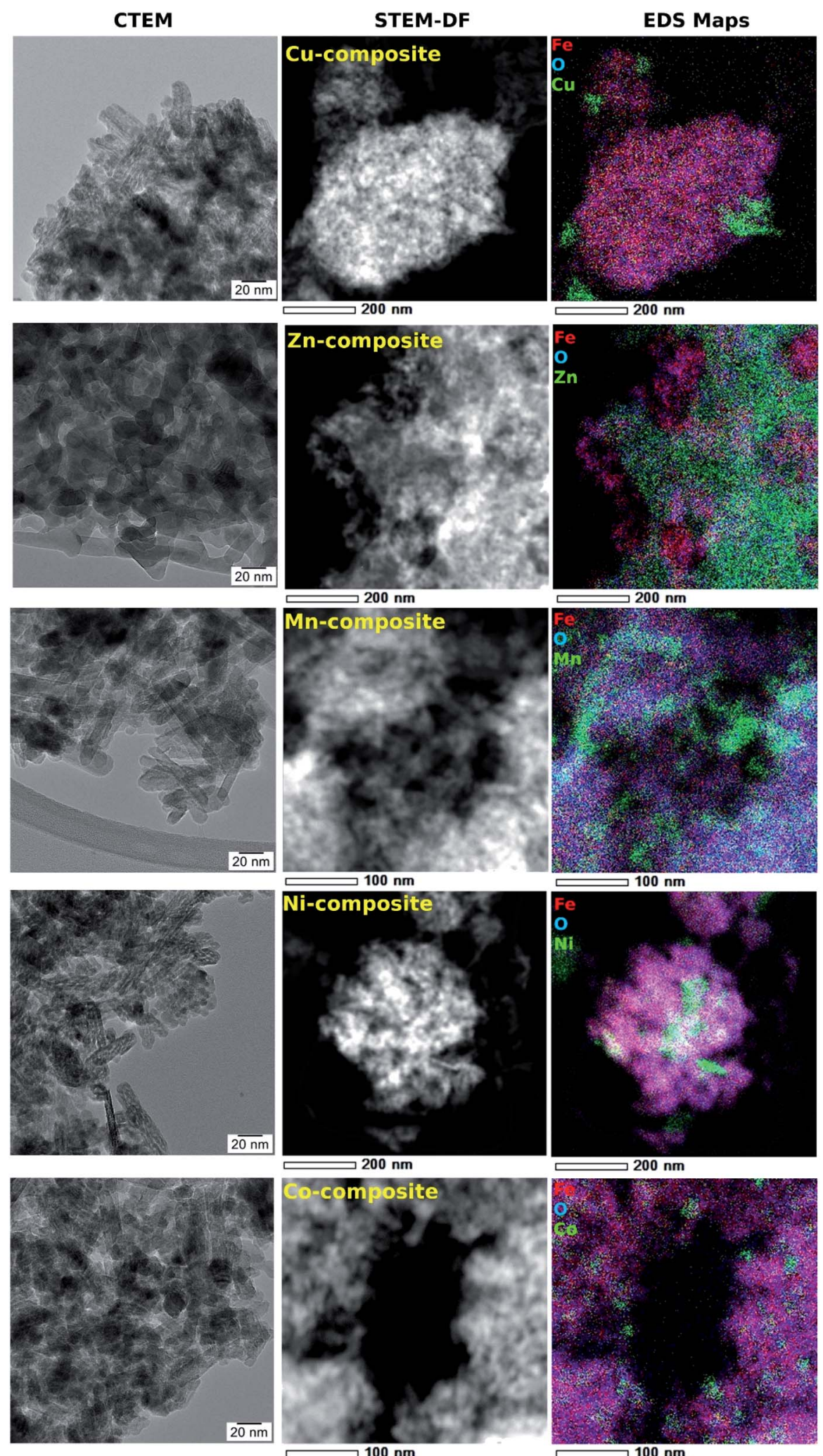

Fig. 6 A comparative TEM study of goethite-based samples.

spectra have been processed at room temperature with distributions of ${ }^{57} \mathrm{Fe}$ positions and low temperature with distinct ${ }^{57} \mathrm{Fe}$ positions.
The room temperature experiments provide only ESI, $\dagger$ and the results are shown in Fig. 3.

The effects related to the presence of $\mathrm{Mn}(\mathrm{III}), \mathrm{Co}(\mathrm{II}), \mathrm{Ni}(\mathrm{II})$, $\mathrm{Cu}(\mathrm{II})$, and $\mathrm{Zn}(\mathrm{II})$ in the $\alpha-\mathrm{FeO}(\mathrm{OH})$ structure have been followed 
according to the variation of the hyperfine parameters. The fit results are shown in Table 3. The quadrupole splitting (QUA) and the magnetic hyperfine field BHF values are in good agreement with specific values of $\alpha-\mathrm{FeO}(\mathrm{OH})$. The isomer shift (ISO), as well as the spectral line width (WID), do not show significant variations among the investigated samples.

In the case of the Mn-composite, the additional presence of a quadrupole doublet can be associated with a small fraction of very fine $\mathrm{FeO}(\mathrm{OH})$ nanoparticles in a magnetic relaxation regime. According to this specific evolution of the Mossbauer hyperfine parameters (almost unchanged among the analyzed samples), we conclude that the structure of the $\alpha-\mathrm{FeO}(\mathrm{OH})$ remains unaffected by the presence of the second transition metallic ion.

\section{X-ray powder diffraction}

The main crystalline phase was identified for all samples as $\alpha$ $\mathrm{FeO}(\mathrm{OH})$ (PDF. No. 1008766). Fig. 4 shows the X-ray powder diffractograms for goethite and goethite-based nanocomposites.

From the Rietveld refinement data (Table 4), it can be observed that the mean crystallite size varies slightly between the goethite and the goethite-based nanocomposites. Such an effect may appear if a doping process of the goethite is considered. Moreover, except for Zn-composite, a slight increase in the lattice parameters can be observed for the other goethite-based nanocomposites. The Zn-composite lattice parameters are approximately the same as for $\mathrm{FeO}(\mathrm{OH}) \cdot \mathrm{H}_{2} \mathrm{O}$. As shown in Fig. 4 and Table 4 , for the $\mathrm{Cu}$-composite and $\mathrm{Zn}$ composite, along with the $\alpha-\mathrm{FeO}(\mathrm{OH})$ phase, another phase $(\mathrm{s})$ appears. In the X-ray diffractogram of $\mathrm{Cu}$-composite, a $\mathrm{CuO}$ phase (tenorite) was identified based on the JCPDS no. 1526990, with the lattice parameters determined by Rietveld refinement analysis as presented in Table 4 . Based on the two intense diffraction peaks at small angles $\left(12^{\circ}\right)$ and the other three peaks at $24.2,24.8$, and $27.3^{\circ}$, copper(II) acetate (JCPDS no. 00-0271126) can be identified along with goethite and copper(II) oxide. The X-ray diffractogram of Zn-composite contains diffraction peaks assigned to the $\mathrm{ZnO}$ phase with a hexagonal structure based on the JCPDS no. 89-1397.

\section{Transmission electron microscopy investigations}

In Fig. 5, the TEM image and corresponding diffraction pattern acquired on $\mathrm{FeO}(\mathrm{OH})$ sample, as a reference, show a nano rodlike morphology and the $\alpha$-phase of $\mathrm{FeO}(\mathrm{OH})(\mathrm{CIF} 1008766)$. The crystalline nanorods have a relatively uniform width (5-10 nm) and a large distribution of lengths, with an average of roughly $40 \mathrm{~nm}$.

The $\mathrm{FeO}(\mathrm{OH})$ phase's morphology tends to be preserved along with the entire series of samples, as shown in Fig. 6. It is worth mentioning that the $\sim 20 \mathrm{~nm}$ size as provided by Rietveld analysis for the $\mathrm{FeO}(\mathrm{OH})$ phase in all cases is a very rough estimation, given the elongated morphology of the entities. The energy-dispersive X-ray spectroscopy (EDX) maps in Fig. 6 shows a specific aggregation of the doping element for all the nanomaterials. In the case of $\mathrm{Cu}$-composite, the TEM investigations correlated with Rietveld refinement suggest the formation of a CuO (JCPDS no. 526990, tenorite) secondary phase. In the case of the Zn-composite, the elemental mapping (Fig. 6), the TEM image, and electron diffraction (Fig. 7, a and b) show the presence of a relatively thin layer of highly textured $\mathrm{ZnO}$ along with the familiar $\mathrm{FeO}(\mathrm{OH})$ phase. This solves the issue regarding the unidentified secondary phase from the Rietveld refinement mentioned above.

For the rest of the samples (Mn-composite, Ni-composite, and Co-composite), the elemental mappings analyzed in correlation with the powder X-ray diffraction results suggest the formation of incoherent $\mathrm{Mn}$ (III), $\mathrm{Ni}(\mathrm{II})$, respectively $\mathrm{Co}$ (II) rich entities.

\section{Textural characterization}

Textural characterization of the samples was carried out by $\mathrm{N}_{2}$ adsorption-desorption analysis. According to the IUPAC classification, all the isotherms (Fig. 8) are of type IV. ${ }^{51}$ It can be noticed that in the region of low relative pressures $\left(p / p_{0}\right)$ up to 0.4 , the amount of $\mathrm{N}_{2}$ adsorbed increases sharply. As $p / p_{0}$ rises above 0.4 , the uptake of $\mathrm{N}_{2}$ is slower, while at $p / p_{0}$ values higher than 0.8 , the adsorption curve tends to flatten. All isotherms display $\mathrm{H} 2$ hysteresis loops due to capillary condensation in mesopores, whose area differs depending on the pore size. The pore size distribution (insets of Fig. 8) obtained using a DFT model is multimodal. The average pore size is around $3 \mathrm{~nm}$ for goethite and M-composites (M: Mn, Co, Ni and $\mathrm{Zn}$ ), while for the $\mathrm{Cu}$-composite, it is $4.05 \mathrm{~nm}$. The goethite has a specific surface area $\left(S_{\mathrm{BET}}\right)$ of $394 \mathrm{~m}^{2} \mathrm{~g}^{-1}$, while for the composites, the $S_{\text {BET }}$ is lower but over $300 \mathrm{~m}^{2} \mathrm{~g}^{-1}$ (Table 5). The obtained $S_{\text {BET }}$ values are much higher than those reported by other authors for similar materials. ${ }^{52}$

\section{Catalytic activity}

In addition to the large numbers of chemical reactions that show a peculiar scientific and economic interest, oxidation plays a crucial role. Selective oxidation, in particular selective oxidation of alkenes, is by far the most widely used method by which oxygen atoms can be inserted into molecules without leading to mineralization. ${ }^{53}$ Epoxides are important functional intermediates playing a crucial role in pharmaceuticals,
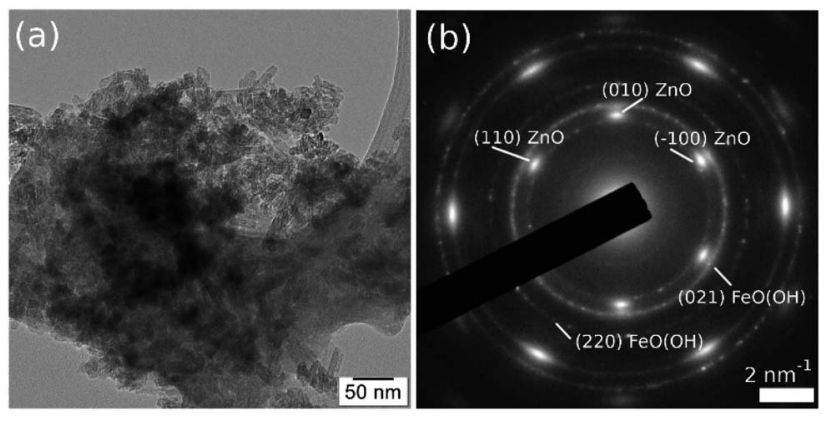

Fig. 7 TEM image (a) and SAED pattern (b) obtained on Zn-composite sample, showing the formation of a highly textured $\mathrm{ZnO}$ secondary phase, oriented in (001) zone axis. 

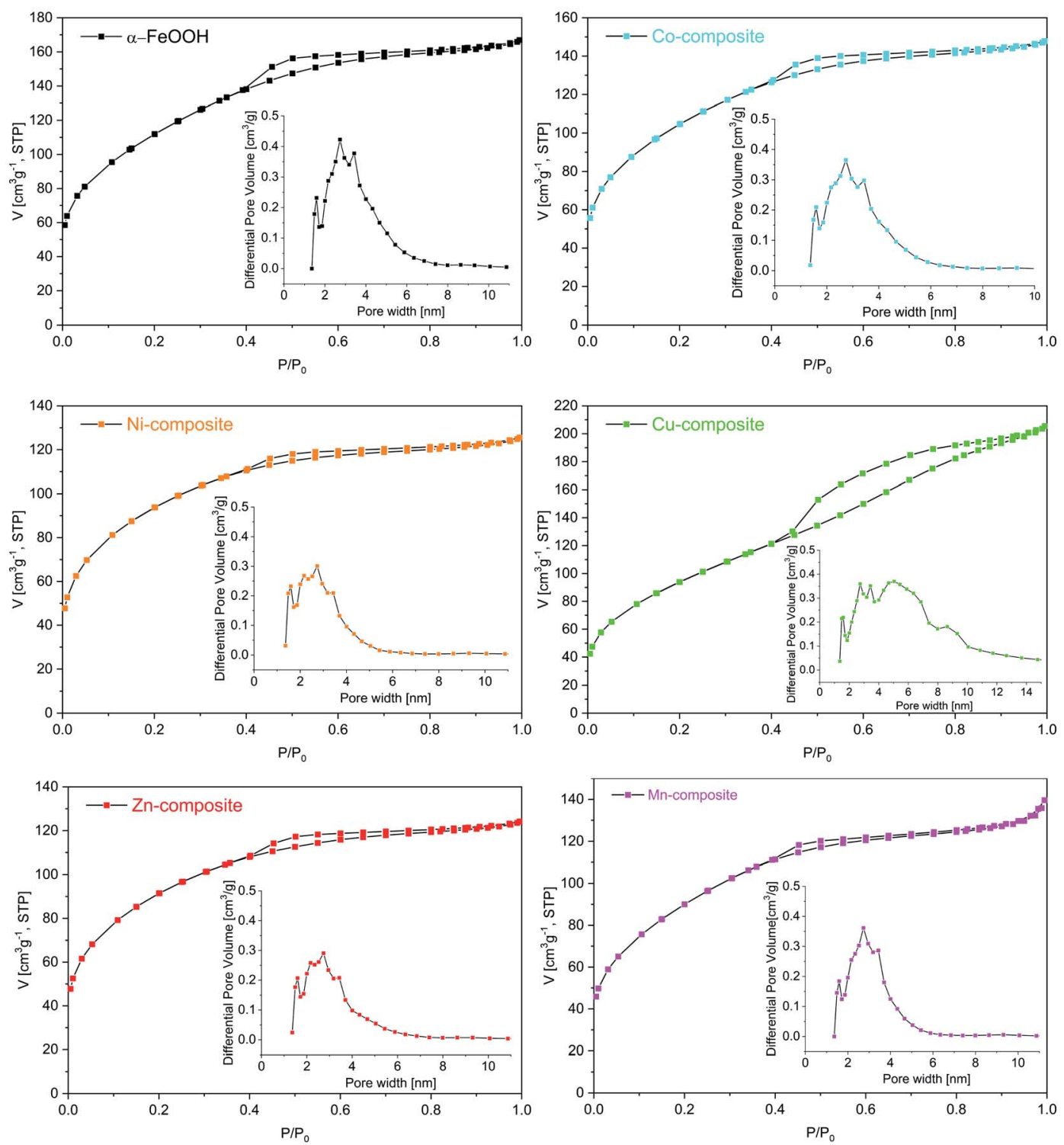

Fig. $8 \mathrm{~N}_{2}$ adsorption-desorption isotherms of the samples (inset: pore size distribution).

Table 5 Textural parameters of the samples

\begin{tabular}{llll}
\hline Sample & $S_{\text {BET }}\left(\mathrm{m}^{2} \mathrm{~g}^{-1}\right)$ & $\begin{array}{l}\text { Pore volume } \\
\left(\mathrm{cm}^{3} \mathrm{~g}^{-1}\right)\end{array}$ & $\begin{array}{l}\text { Average pore } \\
\text { size }(\mathrm{nm})\end{array}$ \\
\hline$\alpha-\mathrm{FeO}(\mathrm{OH})$ & 394 & 0.258 & 3.03 \\
Co-composite & 364 & 0.228 & 2.95 \\
Ni-composite & 321 & 0.194 & 2.91 \\
Cu-composite & 342 & 0.317 & 4.05 \\
Zn-composite & 314 & 0.192 & 2.95 \\
Mn-composite & 320 & 0.215 & 3.20
\end{tabular}

pesticides, cosmetics, and materials production. ${ }^{54}$ However, the selective oxidation of alkenes requires complexes based on homogeneous ${ }^{55-57}$ or heterogeneous ${ }^{58-61}$ catalysts. Almost all of these catalysts have been used in the presence of nonenvironmentally friendly oxidizing agents such as $\mathrm{NaClO},{ }^{62}$
PhIO, ${ }^{63}$ dioxiranes, ${ }^{64}$ tert-butylhydroperoxide, ${ }^{65}$ or potassium peroxomonosulfate. ${ }^{66}$ Hydrogen peroxide or molecular oxygen are viable alternatives to those described above. Up to date, there are several studies concerning epoxidation of alkenes in aerobic conditions using transitional metal complexes/support as catalysts and isobutyraldehyde as reductant, which are carried out in mild conditions. ${ }^{67,68}$

Total conversion of cyclooctene to the corresponding epoxide was recently reported for catalysts consisting of $\mathrm{Co}$ (II) complexes with Schiff base ligands supported on silica-coated magnetite tested under reflux conditions. ${ }^{69}$ However, the synthesis of such catalysts is difficult and expensive, and the energy consumption for heating the reaction mixture is high. Another expensive catalyst that allowed reaching 85\% conversion of cyclooctene with $92 \%$ selectivity for epoxide at a lower temperature (e.g., $35{ }^{\circ} \mathrm{C}$ ) is a $\mathrm{Co}(\mathrm{II})$ coordinated metal-organic framework. ${ }^{70} \mathrm{Co}_{3} \mathrm{O}_{4}$ nanoparticles encapsulated in the inside 
wall of a $m e s o-\mathrm{SiO}_{2}$ shell, which allowed reaching $90 \%$ conversion at $40{ }^{\circ} \mathrm{C},{ }^{71}$ manganese doped cerium oxide catalysts, which allowed getting $80 \%$ conversion at $100{ }^{\circ} \mathrm{C},{ }^{72}$ were recently reported as highly active heterogeneous catalysts for cyclooctene epoxidation using isobutyraldehyde and molecular oxygen. The disadvantages of the latter two systems are that the synthesis of $\mathrm{Co}_{3} \mathrm{O}_{4}$ encapsulated in meso- $\mathrm{SiO}_{2}$ shell catalyst is difficult to control.

In contrast, in the case of Mn-doped cerium oxide catalysts, the reaction conditions involve high energy consumption. Until now, iron oxide hydroxide $(\mathrm{FeOOH})$ was used as an efficient catalyst only for alcohol oxidation, organic sulfide oxidation, and epoxidation of alkenes in the presence of $\mathrm{H}_{2} \mathrm{O}_{2}{ }^{73}$ while the catalytic activity of $\mathrm{FeOOH}$ based nanocomposites containing $\mathrm{MnO}(\mathrm{OH}), \mathrm{Co}(\mathrm{OH})_{2}, \mathrm{Ni}(\mathrm{OH})_{2}$, $\mathrm{CuO}$ or $\mathrm{ZnO}$ in the epoxidation of cyclooctene with molecular oxygen has not been reported. Such catalytic systems could present interest since their synthesis is not difficult and does not imply high costs. The reaction mechanism of cyclooctene oxidation with molecular oxygen in the presence of isobutyraldehyde is analogous to that suggested by Nam and co-workers. ${ }^{74}$ It involves several steps which confirm that the generation of isobutyric acid and the epoxide formation is in a linear dependence (Scheme 1). However, for all the investigated samples, the epoxide selectivity is more than $99 \%$, confirming the unique character of this selective oxidation.

However, several factors limit or improve catalytic activities due to the presence of three various trends. They depend on the cations in the composition of the solids. The lowest cyclooctene conversions of up to $10 \%$, where a plateau level was quickly reached, were obtained with the $\mathrm{Zn}$-composite and $\mathrm{Cu}$ composite samples (Fig. 9). Both $\mathrm{Zn}$ (II) and $\mathrm{Cu}$ (II) cations do not display a large domain of oxidation states, allowing the cations' oxidation-reduction abilities. This characteristic is in agreement with Nam's conclusions, ${ }^{74}$ claiming that the oxidation of olefins occurs in the presence of high-valent oxometal intermediates produced by the reaction of the peroxyacid with the metallic ions from the catalyst. Ni-composite and Cocomposite show a similar variation trend while the plateau level of the conversion is reached after 4 hours. However, the Co-containing catalyst displays better activities than the Ni-

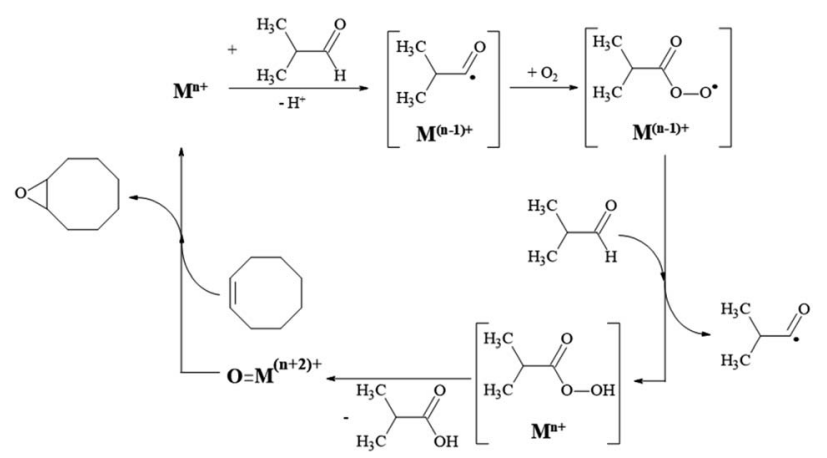

Scheme 1 The reaction mechanism for cyclooctene oxidation with $\mathrm{O}_{2}$ in the presence of isobutyraldehyde. containing one due to its better ability to play the oxidationreduction role.

The goethite $\left(\mathrm{FeO}(\mathrm{OH}) \cdot \mathrm{H}_{2} \mathrm{O}\right)$ and $\mathrm{Mn}$-composite show higher activity values than the other samples. The linear dependence of conversion values versus the reaction time is noticeable. Even after 5 hours, the appearance of a conversion level plateau is not reached.

Considering the result of the acid and base sites determinations presented in Table 6 , there is a clear correlation between the ratio of base sites/acid sites and the conversion values obtained with different catalysts after 5 hours. The manganese presence leads to the best conversion values, which can also be related to the fact that it induces an increased base character of the solid (base sites/acid sites ratio $=4.44$ ).

Moreover, according to the mechanism presented in Scheme 1 , the first step in cyclooctene transformation consists of metal ion reduction. Taking into account the ionization potential $(E)$ associated with each cation presented in the composites $\left(E\left(\mathrm{Mn}^{2+} / \mathrm{Mn}^{3+}\right), 33.69 \mathrm{eV} ; E\left(\mathrm{Co}^{+} / \mathrm{Co}^{2+}\right), 17.03 \mathrm{eV} ; E\left(\mathrm{Ni}^{+} / \mathrm{Ni}^{2+}\right)\right.$, $18.03 \mathrm{eV} ; E\left(\mathrm{Cu}^{+} / \mathrm{Cu}^{2+}\right), 20.29 \mathrm{eV}$ and $\left.E\left(\mathrm{Zn}^{+} / \mathrm{Zn}^{2+}\right), 17.89 \mathrm{eV}\right),{ }^{75}$ it is evident that the reverse transformation will involve the same energy but with an opposite sign. This means that the Mncomposite will provide for the first oxidation step higher energy than the other ones.

Hence, the synergistic effect of the ability to perform oxidation-reduction cycles and the increased base character induced by the involved modifying cations leads to better materials for selective oxidation of olefins. The small fraction of very fine $\mathrm{FeOOH}$ nanoparticles detected by Mössbauer spectra in the Mn-composite sample could also account for its improved activity. The results obtained with the Mn-composite at room temperature were better than those reported for cyclooctene epoxidation using other simple catalytic systems such as $\mathrm{Ni} /$ nanoporous carbon (e.g., 50\% conversion). ${ }^{68}$

The recycling studies for the best material, i.e., $\mathrm{MnFe}_{2} \mathrm{O}_{x}$, indicated its reasonable stability since, after three reaction cycles, the conversion decreases only by $10 \%$ (Fig. 10). The decrease of activity from cycle to cycle could be due to the adsorption of the isobutyric acid generated as a by-product on the base sites of the catalyst since the catalyst was only dried and not washed with solvent before being reused.

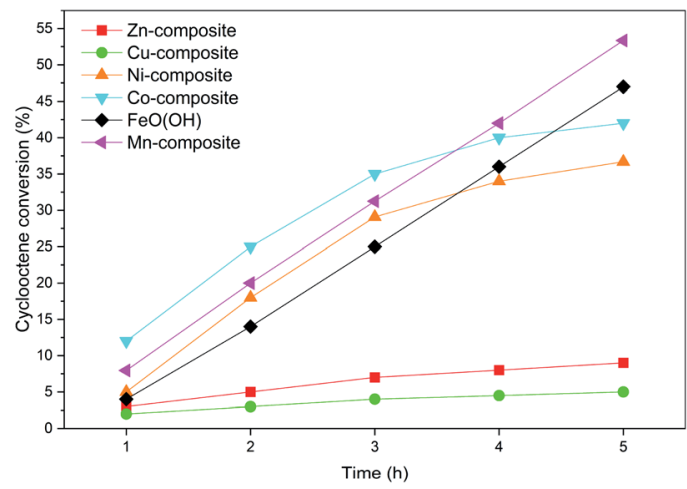

Fig. 9 The samples activities after $5 \mathrm{~h}$ in a cyclooctene oxidation reaction. 
Table 6 Acid-base properties of the investigated samples

\begin{tabular}{|c|c|c|c|c|c|c|}
\hline Composite & $\mathrm{Mn}$ & $\mathrm{Fe}$ & Co & $\mathrm{Ni}$ & $\mathrm{Cu}$ & $\mathrm{Zn}$ \\
\hline Total acidity (mmoles Py per g) & 0.9 & 1.6 & 1.5 & 1.7 & 1.6 & 1.2 \\
\hline$\%$ Bronsted & 21 & 18.1 & 37.9 & 0.0 & 6.7 & 14.5 \\
\hline \% Lewis & 79 & 81.9 & 62.1 & 100.0 & 93.3 & 85.5 \\
\hline Total basicity (mmoles AA per g) & 3.9 & 5.3 & 3.7 & 3.5 & 0.5 & 0.7 \\
\hline Ratio base sites/acid sites & 4.44 & 3.33 & 2.40 & 2.11 & 0.31 & 0.59 \\
\hline
\end{tabular}

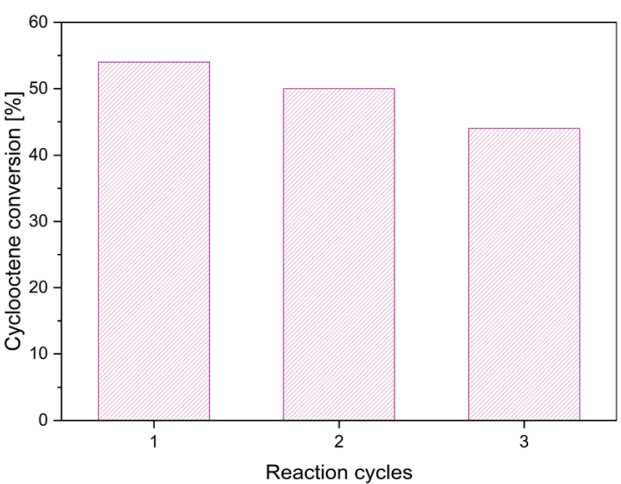

Fig. 10 The cyclooctene conversion in the presence of $\mathrm{Mn}$ composite after three reaction cycles.

\section{Conclusions}

New goethite-based composites containing Mn(III), Co(II), Ni(II), $\mathrm{Cu}(\mathrm{II})$, and $\mathrm{Zn}$ (II) were prepared and characterized from a physicochemical and morphological point of view. The Mössbauer spectra evidenced only the goethite pattern even at low temperatures. In contrast, the different ferromagnetic behavior evidenced by EPR spectra and the characteristic $\mathrm{d}-\mathrm{d}$ bands is consistent with the second transition ion presence in the composite network. The lattice parameters vary only slightly from a composite to other. Powder X-ray diffraction and TEM data indicate a $\mathrm{CuO}$ and $\mathrm{ZnO}$ phase in the corresponding composite. On the other hand, the elemental mappings suggest the rich entities based on $\mathrm{Mn}$ (III), Ni(II), and $\mathrm{Co}(\mathrm{II})$ for the different composites. These data are also consistent with the nano rod-like shape of these materials. The catalytic activity for the selective oxidation of olefins is due to the effect of the redox ability of the modifying cations in the goethite-based nanocomposites and base sites/acid sites ratio. The stability of the modified goethites is sensible due to the action of the isobutyric acid generated as a by-product. The composites will be studied in other catalytic reactions considering that such materials that act at room temperature are easy to synthetized and does not imply high costs. To improve the catalytic abilities, these will be calcined, and the new oxide-based composites will also be tested from this point of view.

\section{Author contributions}

Andrei Cristian Kuncser: conceptualization, data curation, formal analysis, investigation, validation, writing - original draft, writing - review \& editing, Ioana Dorina Vlaicu: onceptualization, data curation, formal analysis, investigation, validation, writing - original draft, writing - review \& editing, Octavian Dumitru Pavel: data curation, formal analysis, investigation, writing - original draft, Rodica Zavoianu: conceptualization, data curation, formal analysis, investigation, supervision, writing - review \& editing, Mihaela Badea: conceptualization, data curation, formal analysis, investigation, Dana Radu: data curation, formal analysis, investigation, validation, writing - original draft, Daniela Cristina Culita: data curation, formal analysis, investigation, Arpad Mihai Rostas: conceptualization, data curation, formal analysis, investigation, validation, writing - original draft, writing - review \& editing, Rodica Olar: conceptualization, data curation, formal analysis, investigation, supervision, validation, writing - original draft, writing - review \& editing.

\section{Conflicts of interest}

There are no conflicts to declare.

\section{Acknowledgements}

The authors: A. C. Kuncser, I. D. Vlaicu, D. Radu, and A. M. Rostas acknowledge the financial support from the Romanian national funding agencies through the project: Core Program PN19-03 (contract no. 21 N/08.02.2019).

\section{Notes and references}

1 M. I. Abdou, H. El-Sayed Ahmed, M. A. Wahab Gaber and A. M. Fadl, Enhancement of anti-corrosion and mechanical properties of alkyd-based protective paints for steel petroleum structures incorporating natural limonite pigment, Cogent Eng., 2018, 5, 1427844, DOI: 10.1080/ 23311916.2018.1427844.

2 E. Ozel, G. Unluturk and S. Turan, Production of brown pigments for porcelain insulator applications, J. Eur. Ceram. Soc., 2006, 26, 735-740, DOI: 10.1016/ j.jeurceramsoc.2005.06.037.

3 Y. Mochizuki and N. Tsubouchi, Thermal Properties of Carbon-Containing Iron Ore Composite Prepared by Vapor Deposition of Tar for Limonite, Metall. Mater. Trans. B, 2019, 50, 2259-2272, DOI: 10.1007/s11663-019-01640-x.

4 X. Zhou, D. Zhu, J. Pan, Y. Luo and X. Liu, Upgrading of High-Aluminum Hematite-Limonite Ore by High 
Temperature Reduction-Wet Magnetic Separation Process, Metals, 2016, 6, 57, DOI: 10.3390/met6030057.

5 B. Oto, N. Yıldız, T. Korkut and E. Kavaz, Neutron shielding qualities and gamma ray buildup factors of concretes containing limonite ore, Nucl. Eng. Des., 2015, 293, 166175, DOI: 10.1016/j.nucengdes.2015.07.060.

6 A. Gur, B. Artig and T. Cakir, Photon attenuation properties of concretes containing magnetite and limonite ores, Physicochem. Probl. Miner. Process., 2017, 53, 184-191, DOI: 10.5277/ppmp170115.

7 N. A. Eissa, M. S. I. Kany, A. S. Mohamed, A. A. Sallam and M. H. El Fouly, Mossbauer spectroscopic study of gamma irradiation on the structural properties of Hematite, Magnetite and Limonite concrete for nuclear reactor shielding, Hyperfine Interact., 1998, 112, 205-212, DOI: 10.1023/a:1011038106201.

8 J.-m. Gaoa, M. Zhang, F. Cheng and M. Guo, Process development for selective precipitation of valuable metals and simultaneous synthesis of single-phase spinel ferrites from saprolite-limonite laterite leach liquors, Hydrometallurgy, 2017, 173, 98-105, DOI: 10.1016/ j.hydromet.2017.08.004.

9 J.-m. Gao and F. Cheng, Facile Synthesis of Magnetically Recyclable Fe2O3-MFe2O4 Photocatalyst from SaproliteLimonite Laterite Leach Liquors, J. Supercond. Novel Magn., 2017, 30, 3339-3343, DOI: 10.1007/s10948-017-4350-8.

10 J.-m. Gao and F. Cheng, Study on the preparation of spinel ferrites with enhanced magnetic properties using limonite laterite ore as raw materials, J. Magn. Magn. Mater., 2018, 460, 213-222, DOI: 10.1016/j.jmmm.2018.04.010.

11 K. B. Dermenci, A. F. Buluç and S. Turan, The effect of limonite addition on the performance of Li7La3Zr2O12, Ceram. Int., 2019, 45, 21401-21408, DOI: 10.1016/ j.ceramint.2019.07.128.

12 F. Xiong, F. Lv, C. Tang, P. Zhang, S. Tan, Q. An, S. Guo and L. Mai, In situ construction of amorphous hierarchical iron oxyhydroxide nanotubes via selective dissolution-regrowth strategy for enhanced lithium storage, Sci. China Mater., 2020, 63, 1993-2001, DOI: 10.1007/s40843-020-1337-5.

13 E. Kavaz and N. Y. Yorgun, Gamma ray buildup factors of lithium borate glasses doped with minerals, J. Alloys Compd., 2018, 752, 61-67, DOI: 10.1016/ j.jallcom.2018.04.106.

14 H. Liu, T. Chen, Q. Xie, X. Zou, C. Chen and R. L. Frost, The functionalization of limonite to prepare NZVI and its application in decomposition of p-nitrophenol, J. Nanopart. Res., 2015, 17, 374, DOI: 10.1007/s11051-015-3171-6.

15 N. O. Camlibel, B. Arik, O. Avinc and A. Yavas, Antibacterial, UV protection, flame retardancy and coloration properties of cotton fabrics coated with polyacrylate polymer containing various iron ores, J. Text. Inst., 2018, 109, 1422-1433, DOI: 10.1080/00405000.2018.1423937.

16 B. G. Kim, J. Park, W. Choi, D. S. Han, J. Kim and H. Park, Electrocatalytic arsenite oxidation using iron oxyhydroxide polymorphs $(\alpha-, \beta-$, and $\gamma-\mathrm{FeOOH})$ in aqueous bicarbonate solution, Appl. Catal., B, 2021, 283, 119608, DOI: 10.1016/ j.apcatb.2020.119608.
17 X. Li, G. Cai, Y. Li, X. Zhu, X. Qi, X. Zhang, B. Shu, K. Li, Y. Wei and H. Wang, Limonite as a source of solid iron in the crystallization of scorodite aiming at arsenic removal from smelting wastewater, J. Clean. Prod., 2021, 278, 123552, DOI: 10.1016/j.jclepro.2020.123552.

18 N. Tsubouchi, H. Hashimito and Y. Ohtsuka, High catalytic performance of fine particles of metallic iron formed from limonite in the decomposition of a low concentration of ammonia, Catal. Lett., 2005, 105, 203-208, DOI: 10.1007/ s10562-005-8691-8.

19 A. Ogawa, Y. Mochizuki and N. Tsubouchi, Catalytic Decomposition of Pyridine with Goethite-Rich Limonite in the Coexistence of Fuel Gas or Coke Oven Gas Components, ISIJ Int., 2016, 56, 1132-1137.

20 Y. Mochizuki, A. Ogawa and N. Tsubouchi, Removal of Hydrogen Sulfide and Ammonia by Goethite-Rich Limonite in the Coexistence of Coke Oven Gas Components, ISIJ Int., 2017, 57, 435-442.

21 T. Kaneko, S. Sugita, M. Tamura, K. Shimasaki, E. Makino and L. H. Silalahi, Highly active limonite catalysts for direct coal liquefaction, Fuel, 2002, 81, 1541-1549, DOI: 10.1016/S0016-2361(02)00079-0.

22 S. S. Sable, P. P. Ghute, P. Álvarez, F. J. Beltrán, F. Medina and S. Contreras, FeOOH and derived phases: Efficient heterogeneous catalysts for clofibric acid degradation by advanced oxidation processes (AOPs), Cat, Today, 2015, 240, 46-54, DOI: 10.1016/j.cattod.2014.03.050.

23 N. A. Mustapha, S. Toya and T. Maeda, Efect of Aso limonite on anaerobic digestion of waste sewage sludge, AMB Express, 2020, 10, 74, DOI: 10.1186/s13568-020-01010-w.

24 R. Pelalak, Z. Heidari, M. Forouzesh, E. Ghareshabani, R. Alizadeh, A. Marjani and S. Shirazian, High performance ozone based advanced oxidation processes catalyzed with novel argon plasma treated iron oxyhydroxide hydrate for phenazopyridine degradation, Sci. Rep., 2021, 11, 964, DOI: 10.1038/s41598-020-80200-9.

25 R. Pelalak, Z. Heidari, R. Alizadeh, E. Ghareshabani, N. Nasseh, A. Marjani, A. B. Albadarin and S. Shirazian, Efficient oxidation/mineralization of pharmaceutical pollutants using a novel Iron (III) oxyhydroxide nanostructure prepared via plasma technology: Experimental, modeling and DFT studies, J. Hazard Mater., 2021, 411, 125074, DOI: 10.1016/j.jhazmat.2021.125074.

26 Y. Fang, X. Cao, W. Zhou, Y. Li, D. M. Johnson and Y. Huang, Catalytic hydrolysis of microcystin-LR peptides on the surface of naturally occurring minerals, Res. Chem. Intermed., 2020, 46, 1141-1152, DOI: 10.1007/s11164-01904024-7.

27 X. Bo, Y. Li, X. Chen and C. Zhao, Operando Raman Spectroscopy Reveals Cr-Induced-Phase Reconstruction of $\mathrm{NiFe}$ and CoFe Oxyhydroxides for Enhanced Electrocatalytic Water Oxidation, Chem. Mater., 2020, 32, 4303-4311, DOI: 10.1021/acs.chemmater.0c01067.

28 X. Cheng, B.-J. Kim, E. Fabbri and T. J. Schmidt, Co/Fe Oxyhydroxides Supported on Perovskite Oxides as Oxygen Evolution Reaction Catalyst Systems, ACS Appl. Mater. 
Interfaces, 2019, 11, 34787-34795, DOI: 10.1021/ acsami.9b04456.

29 B. Shao, W. Pang, X.-Q. Tan, C. Tang, Y. Deng, D. Huang and J. Huang, Rapid growth of amorphous cobalt-iron oxyhydroxide nanosheet arrays onto iron foam: Highly efficient and low-cost catalysts for oxygen evolution, $J$. Electroanal. Chem., 2020, 856, 113621, DOI: 10.1016/ j.jelechem.2019.113621.

30 R. Duan, Y. Li, S. Gong, Y. Tong, Z. Li and W. Qi, Hierarchical CoFe oxyhydroxides nanosheets and Co2P nanoparticles grown on $\mathrm{Ni}$ foam for overall water splitting, Electrochim. Acta, 2020, 360, 136994, DOI: 10.1016/ j.electacta.2020.136994.

31 J. Wang, H. Yin, Z. Chen, G. Cao, N. Xu, H. Wu and P. Wang, A core-shell structured $\mathrm{CoMoO} 4 \cdot \mathrm{nH} 2 \mathrm{O} @ \mathrm{Co} 1-\mathrm{xFexOOH}$ nanocatalyst for electrochemical evolution of oxygen, Electrochim. Acta, 2020, 345, 136125, DOI: 10.1016/ j.electacta.2020.136125.

32 S. Y. Lim, S. Park, S. W. Im, H. Ha, H. Seo and K. T. Nam, Chemically Deposited Amorphous Zn-Doped NiFeOxHy for Enhanced Water Oxidation, ACS Catal., 2020, 10, 235-244, DOI: $10.1021 /$ acscatal.9b03544.

33 C. Liang, P. Zou, A. Nairan, Y. Zhang, J. Liu, K. Liu, S. Hu, F. Kang, H. J. Fan and C. Yang, Exceptional performance of hierarchical Ni-Fe oxyhydroxide@NiFe alloy nanowire array electrocatalysts for large current density water splitting, Energy Environ. Sci., 2020, 13, 86-95, DOI: 10.1039/C9EE02388G.

34 X. Bo, R. K. Hocking, S. Zhou, Y. Li, X. Chen, J. Zhuang, Y. Du and C. Zhao, Capturing the active sites of multimetallic (oxy) hydroxides for the oxygen evolution reaction, Energy Environ. Sci., 2020, 13, 4225-4237, DOI: 10.1039/D0EE01609H.

35 B. Zhang, X. Zheng, O. Voznyy, R. Comin, M. Bajdich, M. García Melchor, L. Han, J. Xu, M. Liu, L. Zheng, F. P. G. de Arquer, C. T. Dinh, F. Fan, M. Yuan, E. Yassitepe, N. Chen, T. Regier, P. Liu, Y. Li, P. D. Luna, A. Janmohamed, H. L. Xin, H. Yang, A. Vojvodic and E. H. Sargent, Homogeneously dispersed multimetal oxygen-evolving catalysts, Science, 2016, 352, 333-337, DOI: 10.1126/science.aaf1525.

36 X. Bo, Y. Li, X. Chen and C. Zhao, High valence chromium regulated cobalt-iron-hydroxide for enhanced water oxidation, J. Power Sources, 2018, 402, 381-387, DOI: 10.1039/C5CC08845C.

37 X. Bo, K. Dastafkan and C. Zhao, Design of Multi-MetallicBased Electrocatalysts for Enhanced Water Oxidation, ChemPhysChem, 2019, 20, 2936-2945, DOI: 10.1002/ cphc.201900507.

38 K. Abuzarova and O. Korchuganova, Nanosized Iron Oxyhydroxide: Properties, Application, Preparation, J. Phys., 2020, 1534, 012002, DOI: 10.1088/1742-6596/1534/1/012002.

39 L. A. Frolova and T. V. Hrydnieva, Influence of various factors on the ferric $\alpha$-oxyhydroxide synthesis, $J$. Chem. Technol., 2020, 28, 61-67, DOI: 10.15421/082008.

40 G. Buxbaum, G. Pfaff, Industrial Inorganic Pigments, WileyVCH Verlag GmbH \& Co KGaA, Weinheim, 3rd edn, 2005.
41 R. Olar, M. Badea, L. Diamandescu, E. Cristurean, D. Marinescu, D. Mihaila-Tarabasanu, N. Stanica and M. Brezeanu, Soft chemical synthesis and characterization of some substituted ferrites, J. Alloys Compd., 2004, 363, 257-267, DOI: 10.1016/S0925-8388(03)00452-3.

42 J. Bassett, R. C. Denney, G. H. Jeffery, J. Mendham, Vogel's text of quantitative inorganic analysis, The English Language Book Society and Longman, London, 4th edition, 1978.

43 H. M. Rietveld, A profile refinement method for nuclear and magnetic structures, J. Appl. Crystallogr., 1969, 2, 65-71, DOI: 10.1107/S0021889869006558.

44 R. Ionescu, O. D. Pavel, R. Bîrjega, R. Zăvoianu and E. Angelescu, Epoxidation of Cyclohexene With $\mathrm{H} 2 \mathrm{O} 2$ and Acetonitrile Catalyzed by Mg-Al Hydrotalcite and Cobalt Modified Hydrotalcites, Catal. Lett., 2010, 134, 309-317, DOI: $10.1007 / \mathrm{s} 10562-009-0238-\mathrm{y}$.

45 G. A. Eimer, S. G. Casuscelli, C. M. Chanquia, V. Elías, M. E. Crivello and E. R. Herrero, The influence of Tiloading on the acid behavior and on the catalytic efficiency of mesoporous Ti-MCM-41 molecular sieves, Catal. Today, 2008, 133-135, 639-646, DOI: 10.1016/j.cattod.2007.12.096.

46 H. Song, J. Wang, Z. Wang, H. Song, F. Li and Z. Jin, Effect of titanium content on dibenzothiophene HDS performance over Ni2P/Ti-MCM-41 catalyst, J. Catal., 2014, 311, 257-265, DOI: 10.1016/j.jcat.2013.11.021.

47 C. A. Emeis, Determination of Integrated Molar Extinction Coefficients for Infrared Absorption Bands of Pyridine Adsorbed on Solid Acid Catalysts, J. Catal., 1993, 141, 347354, DOI: 10.1006/jcat.1993.1145.

48 H. D. Ruan, R. L. Frost, J. T. Kloprogge and L. Duang, Infrared spectroscopy of goethite dehydroxylation: III. FTIR microscopy of in situ study of the thermal transformation of goethite to hematite, Spectrochim. Acta, Part A, 2002, 58, 967-981, DOI: 10.1016/S1386-1425(01) 00574-1.

49 A. B. P. Lever, Inorganic electronic spectroscopy, Elsevier, Amsterdam, 1986.

50 R. V. Morris, H. V. Lauer Jr., C. A. Lawson, E. K. Gibson Jr., G. A. Nace and C. Stewart, Spectral and other physicochemical properties of submicron powders of hematite ( $\alpha$-Fe2O3), maghemite $(\gamma$-Fe2O3), magnetite (Fe3O4), goethite $(\alpha-\mathrm{FeOOH})$, and lepidocrocite $(\gamma-\mathrm{FeOOH})$, J. Geophys. Res.: Solid Earth, 1985, 90(B4), 3126-3144, DOI: 10.1029/JB090iB04p03126.

51 K. S. W. Sing, D. H. Everett, R. A. W. Haul, L. Moscou, R. A. Pierotti, J. Rouquerol and T. Siemieniewska, Reporting physisorption data for gas/solid systems with special reference to the determination of surface area and porosity (IUPAC Recommendations 1984), Pure Appl. Chem., 1985, 57, 603-619.

52 T. J. Jiang, X. W. Zhang, C. Xie, X. Y. Wu, C. W. Luo, M. Li and Y. Peng, Effective capture of aqueous uranium using a novel magnetic goethite: Properties and mechanism, J. Solid State Chem., 2021, 300, 122236, DOI: 10.1016/j.jssc.2021.122236.

53 B. Puértolas, A. K. Hill, T. García, B. Solsona and L. TorrenteMurciano, In-situ synthesis of hydrogen peroxide in tandem 
with selective oxidation reactions: A mini-review, Catal. Today, 2015, 248, 115-127, DOI: 10.1016/ j.cattod.2014.03.054.

54 Q. Chen, F. Peng, F. Li, G. Xia, M. Zong and W. Lou, Biocatalytic epoxidation of cyclooctene to 1,2Epoxycyclooctane by a newly immobilized Aspergillus niger lipase, Catalysts, 2020, 10, 781, DOI: 10.3390/catal10070781.

55 T. Tole, J. Jordaan and H. Vosloo, Synthesis and application of the transition metal complexes of $\alpha$-pyridinyl alcohols, $\alpha$ bipyridinyl alcohols, $\alpha, \alpha^{\prime}$-pyridinyl diols and $\alpha, \alpha^{\prime}$-bipyridinyl diols in homogeneous catalysis, Molecules, 2018, 23, 896, DOI: $10.3390 /$ molecules23040896.

56 H. C. Aspinall, Chiral lanthanide complexes: coordination chemistry and applications, Chem. Rev., 2002, 102, 18071850, DOI: 10.1021/cr010288q.

57 C. R. Goldsmith, Aluminum and gallium complexes as homogeneous catalysts for reduction/oxidation reactions, Coord. Chem. Rev., 2018, 377, 209-224, DOI: 10.1016/ j.ccr.2018.08.025.

58 M. Ghazizadeh, A. Badiei and I. Sheikhshoaie, Ironfunctionalized nanoporous silica type SBA-15: Synthesis, characterization and application in alkene epoxidation in presence of hydrogen peroxide, Arabian J. Chem., 2017, 10, S2491-S2498, DOI: 10.1016/j.arabjc.2013.09.016.

59 P.-P. Knops-Gerrits, D. De Vos, F. Thibault-Starzyk and P. A. Jacobs, Zeolite-encapsulated Mn(II) complexes as catalysts for selective alkene oxidation, Nature, 1994, 369, 543-546, DOI: 10.1038/369543a0.

60 D. C. Sherrington, Polymer-supported metal complex alkene epoxidation catalysts, Catal. Today, 2000, 57, 87-104, DOI: 10.1016/S0920-5861(99)00311-9.

61 S. Bawaked, Q. He, N. F. Dummer, A. F. Carley, D. W. Knight, D. Bethell, C. J. Kiely and G. J. Hutchings, Selective oxidation of alkenes using graphite-supported gold-palladium catalysts, Catal. Sci. Technol., 2011, 1, 747-759, DOI: 10.1039/c1cy00122a.

62 R. Luo, R. Tan, Z. Peng, W. Zheng, Y. Kong and D. Yin, Stable chiral salen $\mathrm{Mn}(\mathrm{III})$ complexes with built-in phase-transfer capability for the asymmetric epoxidation of unfunctionalized olefins using $\mathrm{NaOCl}$ as an oxidant, $J$. Catal., 2012, 287, 170-177, DOI: 10.1016/j.jcat.2011.12.016.

63 M. M. T. Khan, D. Chatterjee, Z. Shirin, H. C. Bajaj, M. R. H. Siddiqui, K. Venkatasubramanian and M. M. Bhadbhade, Nitrosyl ethylenediaminetetraacetato ruthemium(III) - an efficient oxygen atom transfer agent for the oxidation of olefins by molecular $\mathrm{O} 2$ and $\mathrm{PhIO}$ through ligand-mediated nitrosyl/nitro couple, J. Mol. Catal., 1992, 72, 271-282, DOI: 10.1016/0304-5102(92) 85005-Z.

64 M. Frohn and Y. Shi, Chiral ketone-catalyzed asymmetric epoxidation of olefins, Synthesis, 2000, 14, 1979-2000, DOI: 10.1055/s-2000-8715.
65 C. Zeng, D. Yuan, B. Zhao and Y. Yao, Highly enantioselective epoxidation of $\alpha, \beta$-unsaturated ketones catalyzed by rare-earth amides $[(\mathrm{Me} 3 \mathrm{Si}) 2 \mathrm{~N}] 3 \mathrm{RE}(\mu-\mathrm{Cl})$ Li(THF)3 with phenoxy-functionalized chiral prolinols, Org. Lett., 2015, 17, 2242-2245, DOI: 10.1021/acs.orglett.5b00833. $66 \mathrm{~W}$. Zhu and W. T. Ford, Oxidation of alkenes with aqueous potassium peroxymonosulfate and no organic solvent, $J$. Org. Chem., 1991, 56, 7022-7026, DOI: 10.1021/jo00025a014.

67 H. Kameyama, F. Narumi, T. Hattori and H. Kameyama, Oxidation of cyclohexene with molecular oxygen catalyzed by cobalt porphyrin complexes immobilized on montmorillonite, J. Mol. Catal. A: Chem., 2006, 258, 172177, DOI: 10.1016/j.molcata.2006.05.022.

68 S. Y. Lim, M. Kang, J. M. Kim and I.-M. Lee, Epoxidation of Simple Alkenes with $\mathrm{O} 2$ and Isobutyraldehyde Catalyzed by Ni Catalysts Deposited on Nanoporous Carbon, Bull. Korean Chem. Soc., 2005, 26, 887-891, DOI: 10.5012/ bkcs.2005.26.6.887.

69 M. Sarkheil, M. Lashanizadegan and M. Ghiasi, High catalytic activity of magnetic Fe3O4@SiO2-Schiff base$\mathrm{Co}(\mathrm{II})$ nanocatalyst for aerobic oxidation of alkenes and alcohols and DFT study, J. Mol. Struct., 2019, 1179, 278288, DOI: 10.1016/j.molstruc.2018.11.016.

70 S. Sha, H. Yang, J. Li, C. Zhuang, S. Gao and S. Liu, Co(II) coordinated metal-organic framework: An efficient catalyst for heterogeneous aerobic olefins epoxidation, Cat, Commun, 2014, 43, 146-150, DOI: 10.1016/ j.catcom.2013.09.014.

71 Z. Li, R. Huang, L. Zhu, X. Zhou, C. Cao and W. A. Song, Co3O4@meso-SiO2 Hollow Nanoreactor Prepared from ZIF-67 as an Efficient Catalyst for Olefin Epoxidation by Oxygen, ChemNanoMat, 2020, 6, 751-754, DOI: 10.1002/ cnma.201900770.

72 S. Dissanayake, N. Vora, L. Achola, Y. Dang, J. He, Z. Tobin, X. Lu, A. Mirich, P.-X. Gao and S. L. Suib, Synergistic catalysis by $\mathrm{Mn}$ promoted ceria for molecular oxygen assisted epoxidation, Appl. Catal., B, 2021, 282, 119573, DOI: 10.1016/j.apcatb.2020.119573.

73 M. Amini, Y. Mousazade, Z. Zand, M. Bagherzadeh and M. M. Najafpour, Ultra-small and highly dispersive iron oxide hydroxide as an efficient catalyst for oxidation reactions: a Swiss-army-knife catalyst, Sci. Rep., 2021, 11, 6642, DOI: 10.1038/s41598-021-85672-x.

74 W. Nam, H. J. Kim, S. H. Kim, R. Y. N. Ho and J. S. Valentine, Metal complex-catalyzed epoxidation of olefins by dioxygen with Co-oxidation of aldehydes. A mechanistic study, Inorg. Chem., 1996, 35, 1045-1049, DOI: 10.1021/ic950782a.

75 P. F. Lang and B. C. Smith, Ionization Energies of Atoms and Atomic Ions, J. Chem. Ed., 2003, 80, 938, DOI: 10.1021/ ed080p938. 